\title{
Peripartum Hysterectomy in Misan Province during 2014-2016
}

\author{
Saba J. Al Heshemi \\ Department of Gynecology \& Obstetrics in College of Medicine, College of Medicine, Misan University, Misan, Iraq \\ Email: drsabaalhashmi@gmail.com
}

How to cite this paper: Al Heshemi, S.J. (2017) Peripartum Hysterectomy in Misan Province during 2014-2016. Open Journal of Obstetrics and Gynecology, 7, 258-268. https://doi.org/10.4236/ojog.2017.72028

Received: January 9, 2017

Accepted: February 25, 2017

Published: February 28, 2017

Copyright $\odot 2017$ by author and Scientific Research Publishing Inc. This work is licensed under the Creative Commons Attribution International License (CC BY 4.0).

http://creativecommons.org/licenses/by/4.0/

\section{(c) (i) Open Access}

\begin{abstract}
Background: Peripartum hysterectomy is the procedure of removing the uterus after vaginal delivery or cesarean birth; it remains a life-saving procedure in cases of severe uterine hemorrhage. Objective: To know the incidence of peripartum hysterectomy in Misan province, what is the main cause of this procedure, and if there is any change in the incidence of this procedure during a 3 year study period. Method: A descriptive cross sectional study was done in Misan province for all cases of peripartum hysterectomy during the period from 2014-2016. All information regarding present pregnancy, previous obstetric history, the cause of peripartum hysterectomy, any complications \& infant outcome, were taken from the case sheet $\&$ from the patients themselves. 50 patients were enrolled in this study, and only 30 patients needed peripartum hysterectomy and 20 patients' uterus were saved by repair surgery. Results: During the study period of 3 years, there was 72,720 deliveries, and during that time 30 peripartum hysterectomies were carried out of the 50 cases studied, which gave an incidence of $0.4 / 1000$ deliveries. The patients were diagnosed as: rupture uterus in $30(60 \%)$ cases, adherent placenta in $14(28 \%)$ \& $6(12 \%)$ cases had atonic uterus. The major postoperative complication was anemia which complicated $23(46 \%)$ cases, \& then bladder injury $5(10 \%)$. Admission to ICU was needed for $24(48 \%)$ cases. There were 32 (64\%) cases needed $\geq 4$ units of blood transfusion. There were 38 (76\%) cases stayed in hospital for $\geq 4$ days. The most common cause for peripartum hysterectomy was for adherent placenta (28\%) \& rupture uterus (20\%). Conclusion: The incidence of peripartum hysterectomy was $0.4 / 1000$ (0.04\%) deliveries. The most common reason behind peripartum hysterectomy was for adherent placenta and next was for uterine rupture. The rate of this procedure was not changed during the study period.
\end{abstract}

\section{Keywords}

Peripartum Hysterectomy, Primary Postpartum Hemorrhage, Rupture Uterus, Adherent Placenta 


\section{Introduction}

Social science research consistently demonstrates the crucial role that the mother plays in the well-being of her children and family. Recent studies highlight how mothers' parenting, \& well-being are correlated with the welfare of their families. [1].

Estimates of maternal mortality ratio (MMR), by United Nations Millennium Development Goal (MDG) region, 2015, found that globally, the MMR fell by nearly $44 \%$ over the past 25 years, to an estimated 216 maternal deaths per 100,000 live births in 2015, from an MMR of 385 in 1990. The highest number of maternal deaths was in developing regions, where MMR accounts for 293, compared to 12 in developed countries [2].

In developed countries for example in United Kingdom, the most recent report by the Confidential Enquiry into Maternal Deaths (CEMD) was published in December 2014, focused on deaths from amniotic fluid embolism, sepsis, haemorrhage [3]. The leading cause of maternal death in Australia was cardiovascular disease, hemorrhage and thromboembolic disease [4].

Almost all maternal deaths (99\%) occur in developing countries. One of the important causes of maternal death in developing countries is primary postpartum hemorrhage (PPH). A systematic review conducted by the world health organization (WHO) found that PPH is the leading cause of maternal mortality in Africa and Asia [5]. Uterine atony is responsible for most cases of PPH. Retained placenta, an invasive placenta, trauma (uterine rupture), \& coagulopathies are other causes [6]. Complications of PPH include anemia [7]. Blood transfusion may be necessary and carries associated risks [8]. In the severe cases, postpartum pituitary necrosis can occur [9]. Occult myocardial ischemia, dilutional coagulopathy, and death also may occur [10].

Peripartum hysterectomy $(\mathrm{PH})$ can be defined as a hysterectomy performed at the time, or within 24 hours, of delivery when all the measures for PPH failed. The most common indication is severe uterine hemorrhage which is most commonly due to abnormal placentation, uterine atony \& uterine rupture [11].

The range of prevalence of $\mathrm{PH}$ is wide $(0.2-5.4 / 1000)$, with the higher figures usually found in low-resource countries. In Netherlands \& one Canadian province the incidence is $0.5 / 1000$ [12]. In Nigeria the incidence is 4 per 1000 births [13]. In Pakistan the reported rate is 5.6 per 1000 births [14], 2.6 per 1000 births in India [15], while in Egypt is 2.24 per 1000 deliveries [16].

We conduct this study because we want to know the rate of $\mathrm{PH}$, what are the main reasons behind this procedure, and if the incidence of this procedure is increasing in the last 3 years in our province.

\section{Material and Methods}

This descriptive cross sectional study was conducted over a period of three years from 2014 through 2016 in the department of obstetrics and gynecology in 2 main hospitals in Misan province which is located in south of Iraq. Data were collected from the maternity units. 
The total number of deliveries during the period of study was 72,720 deliveries. This study was a retrospective and a prospective study. In this study, all cases of uterine atony, rupture uterus, adherent placenta that are presented to maternity unit whether diagnosed in the hospital or referred from district regions were included.

The diagnosis of each of these cases was made through history, examination and during laparotomy. All the information were taken directly from the patients or from the records for the others later. Data were collected regarding patients age, occupation, residency, present pregnancy history, past obstetric history, examination details, management (hysterectomy or uterine repair), indications for $\mathrm{PH}$, postoperative complications, admission to intensive care unit, maternal death and fetal outcome data: term or preterm, alive or dead, admission to neonatal unit or not. 50 patients were enrolled in this study, and only 30 patients needed $\mathrm{PH}$ and 20 patients' uterus were saved by repair surgery.

For this study we use the definition of $\mathrm{PH}$ as any hysterectomy performed within 24 hours of a birth. Data were entered into an Excel database and analyzed as percentage \& figures.

\section{Result}

During the study period of 3 years there was 72720 deliveries, and during that time $30 \mathrm{PH}$ were carried out, which gave an incidence of 0.4/1000 deliveries. Mean maternal age was 32 years with a range $(20$ - 45). Most of our patients were housewives (48) 96\% compared to only 2 (4\%) employers. The study showed that $17(34 \%)$ case were referred from rural regions, while the rest $33(66 \%)$ cases were from urban region. 35 (70\%) patients had $\geq 5$ children \& 15 (30\%) patients had $<5$ children with a range from $(2-9)$. Twenty nine $(58 \%)$ patients have had previous cesarean delivery, while 21 (42\%) were not. From those with previous cesarean delivery, 14 (28\%) women had only one previous cesarean delivery while $15(30 \%)$ had 2 or more previous cesarean. Regarding the mode of delivery, 32 (64\%) patients delivered vaginally while 7 (14\%) patient underwent elective cesarean delivery \& $11(22 \%)$ patients emergency cesarean delivery: 5 (10\%) for dystocia, 4 (8\%) with spontaneous labour \& more than one CD, 2 (4\%) for placenta previa \& 1 (2\%) for abruption. There were 32 (64\%) alive babies, 27 (54\%) term \& $5(10 \%)$ preterm babies. In 18 (36\%) they were dead babies, 15 (30\%) term \& 2(4\%) were preterm babies. There were $11(22 \%)$ died intrapartum, 2 (4\%) were cases of intrauterine fetal death \& 5 (10\%) died in neonatal period (as shown in Table 1 ).

Regarding the patients presentation there was 7 (14\%) cases presented for elective cesarean delivery, \& 43 (64\%) patients their presentation was as follows: spontaneous labour in 15(30\%), induction or augmentation of labour in $5(10 \%)$, antepartum hemorrhage (APH) in $8(16 \%)$, obstructed labour in $3(6 \%)$, hypovolemic shock in 7 (14\%), PPH in 3 (6\%) \& unfortunately 2 arrived dead (4\%). (as shown in Figure 1). 
Table 1. Frequency distribution of the variables within the sample $(n=50)$.

\begin{tabular}{|c|c|c|c|}
\hline \multicolumn{2}{|c|}{ variables } & \multirow{2}{*}{$\begin{array}{c}\text { Freq. } \\
28\end{array}$} & \multirow{2}{*}{$\begin{array}{l}\% \\
56\end{array}$} \\
\hline & $<35$ & & \\
\hline $1 \times \mathrm{ge}$ & $\geq 35$ & 22 & 44 \\
\hline \multirow{2}{*}{ Occupation } & Housewives & 48 & 96 \\
\hline & Employers & 2 & 4 \\
\hline \multirow{2}{*}{ Residency } & Urban & 33 & 66 \\
\hline & Rural & 17 & 34 \\
\hline \multirow{2}{*}{ Gravidity } & $<5$ & 15 & 30 \\
\hline & $\geq 5$ & 35 & 70 \\
\hline \multirow{2}{*}{ Previous cesarean } & Yes & 29 & 58 \\
\hline & No & 21 & 42 \\
\hline \multirow{3}{*}{ Mode of delivery } & Vaginal delivery & 32 & 64 \\
\hline & Elective CD & 7 & 14 \\
\hline & Emergency CD & 11 & 22 \\
\hline \multirow{2}{*}{ Infant outcome } & Alive & 32 & 64 \\
\hline & Dead & 18 & 36 \\
\hline
\end{tabular}

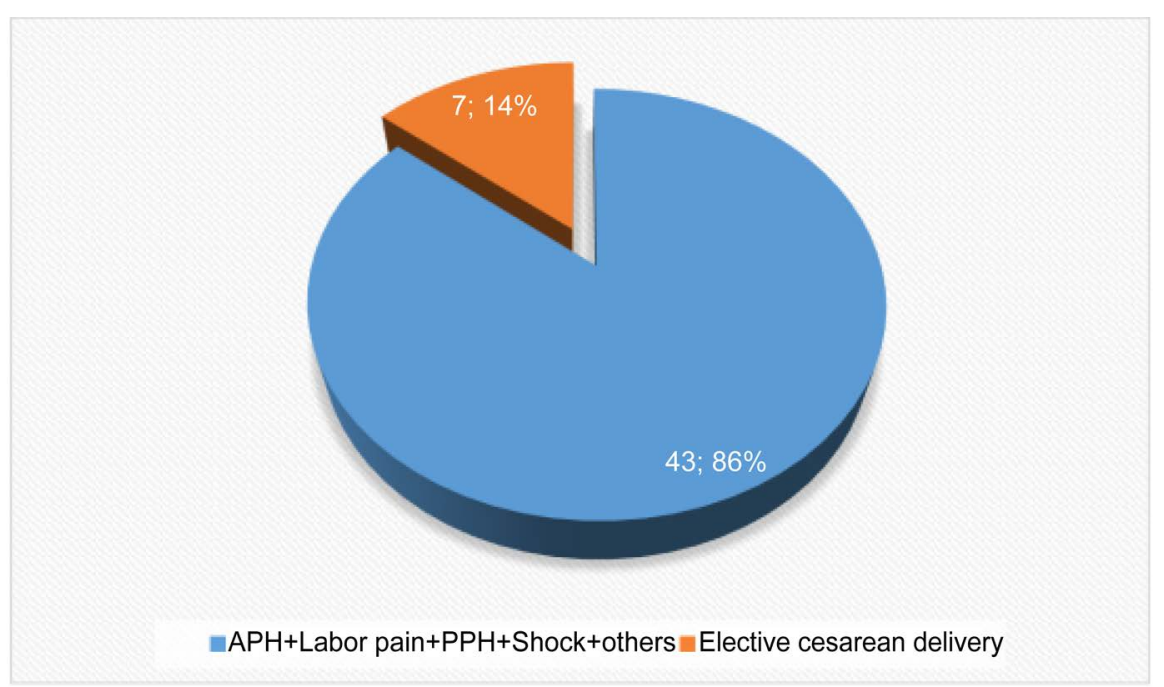

Figure 1. Presentation of the patients within the sample $(n=50)$.

All the studied groups were carrying single baby. The most common pregnancy complication seen was anemia $17(34 \%)$ case, then placenta previa which complicate $14(28 \%)$ case, \& most of those with placenta previa were cases with previous one or more cesarean delivery, $12(24 \%)$ patients with placenta previa were having placenta accrete, most of them diagnosed during surgery. Other pregnancy complications were gestational hypertension (12\%), placental abruption (4\%) (as seen in Figure 2).

Those patients who were admitted with spontaneous labour, induction or augmentation of labour developed vaginal bleeding during labour, as APH in 2 (4\%), \& PPH in 18 (36\%) case (as shown in Table 2). 


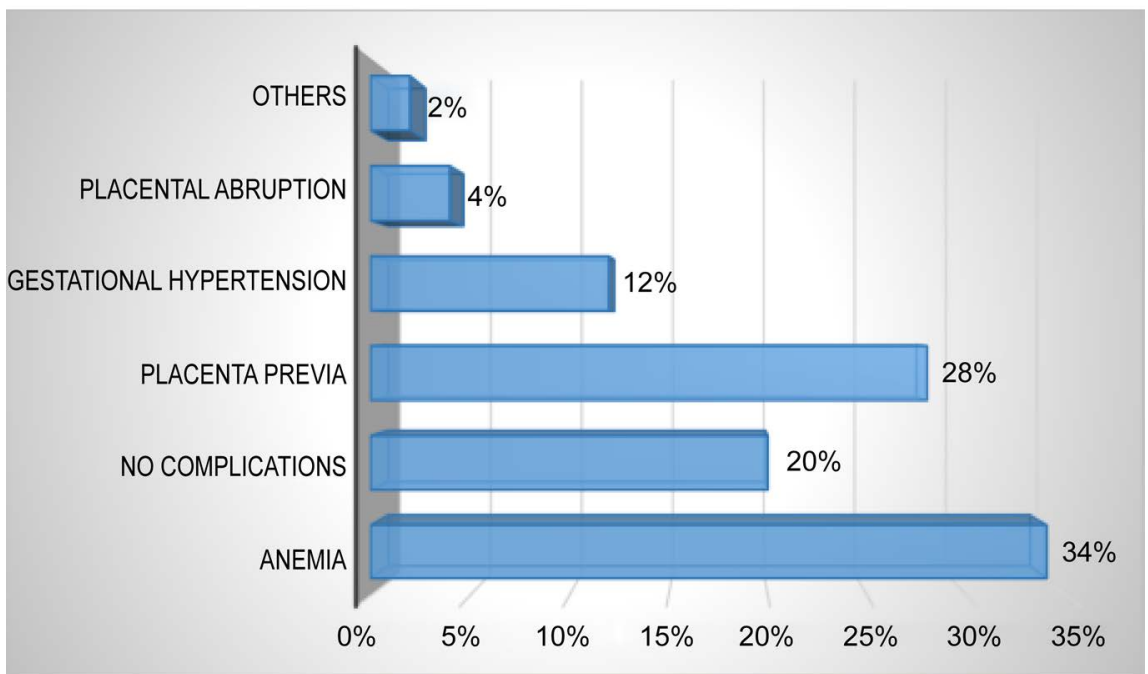

Figure 2. Frequency distribution of any pregnancy complication $(n=50)$.

Table 2. Fate of those patients presented as a case of labour.

\begin{tabular}{ccc}
\hline Fate of labor & & \\
\hline Spontaneous labour & $\mathrm{PPH}=13(26 \%)$ & $\mathrm{APH}=2(4 \%)$ \\
Induction, augmentation & $\mathrm{PPH}=5(10 \%)$ & $\mathrm{APH}=0(0 \%)$ \\
Total & $18(36 \%)$ & $2(4 \%)$ \\
\hline
\end{tabular}

According to the patient presentation and from the intrapartum complication, we had three diagnoses: rupture uterus in $30(60 \%)$, adherent placenta in 14 $(28 \%)$ \& $6(12 \%)$ cases had atonic uterus. Hysterectomy was done in $30(60 \%)$ of cases. In all cases of adherent placenta hysterectomy was done. In cases of atonic uterus and after failure of medical and other surgical alternative, hysterectomy was done. In cases of rupture uterus, hysterectomy was done in $10(20 \%)$ cases and repair with or without tubal ligation in $20(40 \%)$ of cases (as shown in Figure 3).

The next table showed that the major postoperative complication was anemia which complicates $23(46 \%)$ case. The next complication was bladder injury 5 (10\%), 3 (6\%) in cases of rupture uterus \& $2(4 \%)$ associated with adherent placenta. Ureter injury complicated $1(2 \%)$ in a case of rupture uterus. Fever affect $5(10 \%)$, one case was complicated by pelvic abscess. Broad ligament hematoma complicated 3 (6\%). Lastly 3 (6\%) cases, one complicated by basal atelectasis, the other by heart failure \&one with brain infarction. There were $2(4 \%)$ cases needed $2^{\text {nd }}$ look laparotomy to remove pelvic packs. Admission to ICU was needed for $24(48 \%)$ cases. There were $32(64 \%)$ cases needed $\geq 4$ units of blood transfusion. We had $8(16 \%)$ cases needed more than 10 units. There were 38 (76\%) cases stayed in hospital for 4 or more days, the longest period was 14 days because the patient needed dialysis for acute renal failure (as shown in Table 3).

The next table showed the rate of $\mathrm{PH}$ each year during the study period, which was only less during 2015: 0.2/1000 deliveries (as shown in Table 4). 


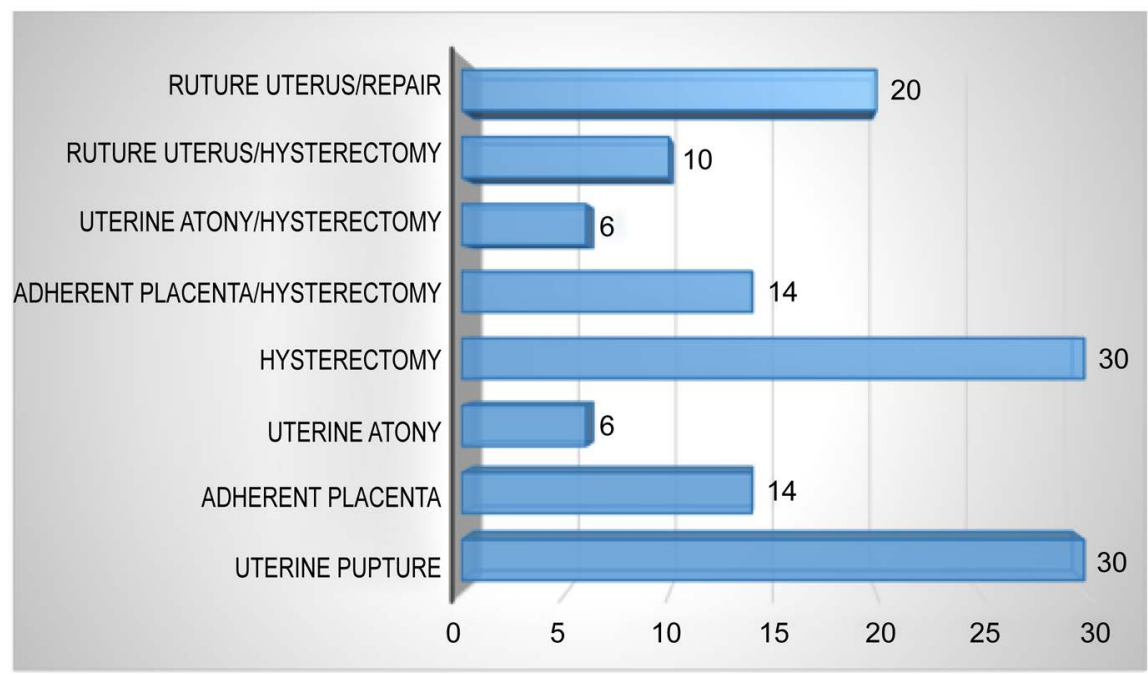

Figure 3. Diagnosis of the patients within the sample $(n=50)$.

Table 3. Intra-\& postoperative complications $(n=50)$.

\begin{tabular}{|c|c|c|c|}
\hline & variable & Freq. & $\%$ \\
\hline \multirow{10}{*}{ Complications } & Anemia & 23 & 46 \\
\hline & Fever & 5 & 10 \\
\hline & Ureter injury & 1 & 2 \\
\hline & Bladder injury & 5 & 10 \\
\hline & Hematoma & 3 & 6 \\
\hline & Acute renal failure & 2 & 4 \\
\hline & $2^{\text {nd }}$ look laparotomy to remove packs & 2 & 4 \\
\hline & $\underline{\text { Others }}$ & 3 & 6 \\
\hline & No complications & 5 & 10 \\
\hline & Admission to ICU & 24 & 48 \\
\hline \multirow{2}{*}{$\begin{array}{l}\text { Number of blood } \\
\text { units received }\end{array}$} & $\geq 4$ & 32 & 64 \\
\hline & $<3$ & 18 & 36 \\
\hline \multirow{2}{*}{$\begin{array}{l}\text { Days of stay in hospital } \\
\text { after surgery }\end{array}$} & $\geq 4$ days & 38 & 76 \\
\hline & $<3$ days & 12 & 24 \\
\hline
\end{tabular}

Table 4. The rate of $\mathrm{PH}$ each year during the study period.

\begin{tabular}{cccc}
\hline year & Total number of deliveries & Number of $\mathrm{PH}$ & Rate of $\mathrm{PH} / 1000$ deliveries \\
\hline 2014 & 24563 & 12 & 0.4 \\
2015 & 23503 & 7 & 0.2 \\
2016 & 24654 & 12 & 0.4 \\
total & 72720 & 31 & 0.4 \\
\hline
\end{tabular}


The most common cause of primary $\mathrm{PPH}$ in the study period was rupture uterus $30(60 \%)$ cases, while the rest $20(40 \%)$ were due to adherent placenta 14 $(28 \%)$ \& uterine atony in $6(12 \%)$.

From the 30 case of ruptured uterus during the study period \& out of 72720 total deliveries, the study showed that the incidence of ruptured uterus was $0.04 \%$ or 1 in 2400 deliveries. There was no difference each year in the incidence of ruptured uterus (as seen in Table 5).

The highest incidence of ruptured uterus was seen in women more than 30 years of age and those with more than 5 children. The majority of cases were referred cases from rural areas, but also cases were seen at hospital.

The most common causes of rupture uterus were as follows: obstructed labour $33 \%$, cases with previous cesarean delivery $30 \%$, and in $23 \%$ oxytocin \& prostaglandin were used.

There were 11 fetal deaths, giving $37 \%$ perinatal mortality rate. In $67 \%$ of cases repair of the uterus was done, and only $33 \%$ underwent $\mathrm{PH}$ (as shown in $\mathrm{Ta}$ ble 6).

Table 5. Frequency of rupture uterus in each year $(n=30)$.

\begin{tabular}{ccc}
\hline & Rupture of uterus & \\
\hline year & Freq. & $\%$ \\
\hline 2014 & 13 & 59.1 \\
2015 & 6 & 60 \\
2016 & 11 & 61.1 \\
Total & 30 & 60 \\
\hline
\end{tabular}

Table 6. Frequency distribution of the variables within the sample.

\begin{tabular}{lcc}
\hline \multicolumn{1}{c}{ variables } & Freq. & $\%$ \\
\hline Age $\geq 30$ years & 24 & 80 \\
Parity $\geq 5$ & 21 & 70 \\
Referral & 18 & 60 \\
In hospital & 12 & 40 \\
Risk factors & & \\
1. Obstructed labour & 10 & 33 \\
2. Previous scar & 9 & 30 \\
3. Use of oxytocin \& PG & 7 & 23 \\
4. Precipitate labour & 2 & 7 \\
5. malpresentation & 2 & 7 \\
Baby outcome & Alive 19 & 63 \\
Hysterectomy & Dead 11 & 37 \\
Repair with or without T.L. & 10 & 33 \\
\hline
\end{tabular}




\section{Discussion}

In Misan province (located in the south of Iraq), more than 1,000,000 lives, the number of deliveries in 2014 was 24,563 , which became 24,654 in 2016 . The rate of $\mathrm{PH}$ during the period of the study was $0.4 / 1000(0.04 \%)$ deliveries, which is consistent with other studies: they reported the incidence of $\mathrm{PH}$ as $0.04 \%$ to $0.23 \%$ of deliveries [11] [17] [18], \& the study rate is lower than a study which was conducted in Baghdad province where it was 1.8/1000 deliveries [19].

The incidence of $\mathrm{PH}$ was almost the same in 2014 \& 2016 (0.4/1000 deliveries), \& in 2015 it was $0.2 / 1000$ deliveries, so the incidence was not increased during the period of study, as seen in other studies [20]. The most common causes of $\mathrm{PH}$ in this study were due to morbidly adherent placenta and uterine rupture, which was the same as a study done in Baghdad province [19], but not like other studies which found adherent placenta and uterine atony as major causes of PH [21].

The first indication of $\mathrm{PH}$ in this study was for adherent placenta. The incidence of cesarean delivery in our province was $23 \%$ during the period of study. This explained the high incidence of $\mathrm{PH}$ in cases of previous cesarean delivery especially those with 2 or more cesareans, and this result is the same as seen in other studies [22].

In this study we had $12(24 \%)$ cases with placenta accrete and a history of previous $2 \&$ more cesarean deliveries. Two or more prior cesarean deliveries increase the likelihood of cesarean hysterectomy 18-fold [22].

The second indication for $\mathrm{PH}$ was found in cases of ruptured uterus. Incidence of ruptured uterus in our study was $0.04 \%$ or 1 in 2400 deliveries, which is lower than a study done in Dohuk, Iraq which was 1 in 490 deliveries [23], and lower than the incidence in Nigeria or Africa $(0.2 \%-0.9 \%)$ [24]. Uterine rupture in an unscarred uterus occurs extremely rarely (6.1/10,000 deliveries) [25]. Following a previous caesarean section the incidence increases to $22-74 / 10,000$ deliveries if vaginal birth after caesarean (VBAC) is attempted [26].

The main risk factors for ruptured uterus in this study were obstructed labour in $33 \%$, history of previous cesarean delivery in $30 \%$ and the use of oxytocin, prostaglandin in $23 \%$ of cases. These findings were similar to other studies [23] [24]. In this study there were $21(70 \%)$ of cases with high parity which was also a risk factor. From these risk factors \& a delay in the referral of cases from rural areas with the malpractice in the hospital and from the midwives during labour all these increased the risk for rupture uterus.

The last cause of $\mathrm{PH}$ in this study was uterine atony in 6 (12\%) cases. This result was the same as a study in Baghdad province [19] that the last cause of PH was uterine atony, but is not like a study in Turkey that they found uterine atony as the main cause for $\mathrm{PH}[27]$.

All patients in this study received conservative management to treat uterine atony, uterotonic agents, bimanual uterine massage, if failure then surgical management was initiated starting with bilateral uterine artery ligation, bilateral internal iliac artery ligation to B-Lynch suture, and lastly but in the proper time 
PH was done.

Severe maternal morbidity has been issued by American college of obstetrician and gynecologist (ACOG) and the society for maternal fetal medicine (SMFM). They said if one of two criteria is met in any case: transfusion of at least four units of blood or intensive care unit admission of a pregnant or postpartum woman, this case has severe maternal morbidity which if not identified, would lead to maternal death [28].

In this study there were 32 (64\%) cases, received more than 4 units of blood, in a range of $4-18$ units of blood. And the study showed that $24(48 \%)$ cases admitted to intensive care unit. These results showed that we have severe maternal morbidity during the study period. All this may be related to poor antenatal care, delay in the transfer \& mismanagement in the hospitals. Unfortunately during the study period there were 2 maternal deaths.

From this study we can see that the main cause of $\mathrm{PH}$ was for adherent placenta \& uterine rupture. The reasons for the rupture uterus may be: poor birth practices, inadequate referral and emergency obstetric care, and a high level of anemia among pregnant women, especially among rural women in the center and south of Iraq [29].

Proper prenatal care is important for the wellbeing of the mother during pregnancy, those who don't get proper prenatal care run the risk that such pregnancy related complications won't be detected or won't be dealt with soon enough, \& that can lead to potentially serious consequences for both the mother and her baby [30].

The limitation of the study may be attributed to the following facts:

1) In our region when the mother dies during or immediately after delivery, her family buried her without knowing the cause of death. The families refuses autopsy because of religious and cultural reasons.

2) Home delivery is a common practice in our region, with all related unrecorded risks done by midwives and other poor practices in the country side.

\section{References}

[1] Moro-Egio, A.I. (2012) Changing Trends of Mothers' Active and Passive Childcare Times. Journal of Family Economic Issues, 33, 11-23.

[2] WHO, UNICEF, UNFPA, World Bank Group, and the United Nations Population Division (2015) Trends in Maternal Mortality: 1990 to 2015. World Health Organization, Geneva.

[3] MBRRACE-UK: Mothers and Babies: Reducing Risk through Audits and Confidential Enquiries across the UK2014 Report (pdf) Lay Summary.

http://www.npeu.ox.uk/mbrrace-uk

[4] http://www.aihw.gov.au/publication-detail/?id=60129551119\&tab

[5] Khan, K.S., Wojdyla, D., Say, L., Gümezoglu, A.M. and Look, P.F.A. (2006) WHO Analysis of Causes of Maternal Death: A Systematic Review. The Lancet, 367, 10661074.

[6] Anderson, J.M. and Etches, D. (2007) Prevention and Management of Postpartum Hemorrhage. American Family Physician, 75, 875-882. 
[7] Corwin, E.J., Murray-Kolb, L.E. and Beard, J.L. (2003) Low Hemoglobin Level Is a Risk Factor for Postpartum Depression. Journal of Nutrition, 133, 4139-4142.

[8] Ekeroma, A.J., Ansari, A. and Stirrat, G.M. (1997) Blood Transfusion in Obstetrics and Gynaecology. British Journal of Obstetrics and Gynaecology, 104, 278-284.

[9] Willis, C.E. and Livingstone, V. (1995) Infant Insufficient Milk Syndrome Associated with Maternal Postpartum Hemorrhage. Journal of Human Lactation, 11, 123-126.

[10] Reyal, F., Deffarges, J., Luton, D., Blot, P., Oury, J.F. and Sibony, O. (2002) Severe Post-Partum Hemorrhage: Descriptive Study at the Robert-Debre Hospital Maternity Ward [French]. Journal De Gynecologie, Obstetrique et Biologie De La Reproduction (Paris), 31, 358-364.

[11] Flood, K.M., Said, S., Geary, M., Robson, M., Fitzpatrick, C. and Malone, F.D. (2009) Changing Trends in Peripartum Hysterectomy over the Last 4 Decades. American Journal of Obstetrics \& Gynecology, 200, 632.e1-632.e6.

[12] Kwee, A., Bots, M.L., Visser, G.H. and Bruinse, H.W. (2006) Emergency Peripartum Hysterectomy: A Prospective Study in the Netherlands. European Journal of Obstetrics \& Gynecology and Reproductive Biology, 124, 187-192.

[13] Omole-Ohonsi, A. and Olayinka, H.T. (2012) Emergency Peripartum Hysterectomy in a Developing Country. Journal of Obstetrics and Gynaecology Canada, 34, 954960.

[14] Nasima, S., Asifa, G., Shazia, J. and Tehmina, A. (2007) Emergency Obstetric Hysterectomy (EOH): A Life Saving Procedure in Obstetrics. Pakistan Journal of Surgery, 23, 217-219.

[15] Anita, K. and Kavita, W.W. (2005) Emergency Obstetric Hysterectomy. Journal of Obstetrics and Gynecology of India, 55, 132-134.

[16] Allam, I.S., Gomaa, I.A., Fathi, H.M. and Sukkar, G.F. (2014) Incidence of Emergency Peripartum Hysterectomy in Ain-Shams University Maternity Hospital, Egypt: A Retrospective Study. Archives of Gynecology and Obstetrics, 290, 891-896.

[17] Whiteman, M.K., Kuklina, E., Hillis, S.D., et al. (2006) Incidence and Determinants of Peripartum Hysterectomy. Obstetrics \& Gynecology, 108, 1486-1492.

[18] Rossi, A.C., Lee, R.H. and Chmait, R.H. (2010) Emergency Postpartum Hysterectomy for Uncontrolled Postpartum Bleeding: A Systematic Review. Obstetrics \& Gynecology, 115, 637-644.

[19] Al-Hamadani, I., Ahmed, A.T. and Mohammed, S. (2012) Emergency Obstetric Hysterectomy in Elywia Maternity Teaching Hospital Baghdad. The Iraqi Postgraduate Medical Journal, 11, 712-717.

[20] Whiteman, M.K., Kuklina, E., Hillis, S.D., Jamieson, D.J., Meikle, S.F., Posner, S.F. and Marchbanks, P.A. (2006) Incidence and Determinants of Peripartum Hysterectomy. Obstetrics \& Gynecology, 108, 1486-1492.

[21] Glaze, S., et al. (2008) Peripartum Hysterectomy 1999 to 2006. Obstetrics \& Gynecology, 111, 732-738.

[22] Knight, M., Kurinczuk, J.J., Spark, P. and Brocklehurst, P. (2008) United Kingdom Obstetric Surveillance System Steering Committee. Cesarean Delivery and Peripartum Hysterectomy. Obstetrics \& Gynecology, 111, 97-105.

[23] Yalda, M.A. and Munib, A. (2009) Uterine Rupture in Dohuk, Iraq. Eastern Mediterranean Health Journal, 15, 1272-1277.

[24] Rotimi, E.O. and Olamijulo, J.A. (1998) Rupture of the Uterus at the Lagos University Teaching Hospital, Lagos, Nigeria. West African Journal of Medicine, 17, 188193. 
[25] Zwart, J.J., Richters, J.M., Ory, F., et al. (2008) Severe Maternal Morbidity during Pregnancy, Delivery and Puerperium in the Netherlands: A Nationwide Population-Based Study of 371,000 Pregnancies. BJOG, 115, 842-850.

[26] Birth after Previous Caesarean Birth (2007) Royal College of Obstetricians and Gynaecologists.

[27] Tapisiz, O.L, Altinbas, S. and Yirci, B. (2012) Emergency Peripartum Hysterectomy in a Tertiary Hospital in Ankara, Turkey: A 5 Year Review. Archives of Gynecology, 286, 1131-1134.

[28] Troy Brown, R.N. (2016) ACOG, SMFM Update Guidance on Severe Maternal Morbidity. Medscape Medical News.

[29] http://www.emro.who.int/irq/programmes/maternal-newborn-child-adolescent-hea lth.html

[30] http://kidshealth.org/en/parents/medical-care-pregnancy.html

\section{Scientific Research Publishing}

Submit or recommend next manuscript to SCIRP and we will provide best service for you:

Accepting pre-submission inquiries through Email, Facebook, LinkedIn, Twitter, etc. A wide selection of journals (inclusive of 9 subjects, more than 200 journals)

Providing 24-hour high-quality service

User-friendly online submission system

Fair and swift peer-review system

Efficient typesetting and proofreading procedure

Display of the result of downloads and visits, as well as the number of cited articles

Maximum dissemination of your research work

Submit your manuscript at: http://papersubmission.scirp.org/

Or contact ojog@scirp.org 